\title{
Neutrophil to lymphocyte ratio as noninvasive predictor of pulmonary vascular resistance increase in congestive heart failure patients: Single-center preliminary report
}

\author{
Tomasz Kamil Urbanowicz ${ }^{1, A-F}$, Anna Olasińska-Wiśniewska ${ }^{2, C-F}$, \\ Michał Michalak ${ }^{3, C, E}$, Ewa Straburzyńska-Migaj ${ }^{4, A, B, D-F}$, Marek Jemielity ${ }^{2, A, E, F}$ \\ ${ }^{1}$ Cardiac Surgery and Transplantology Department, University Hospital of Lord's Transfiguration, Poznan University of Medical Sciences, Poland \\ 2 Department of Cardiac Surgery and Transplantology, Poznan University of Medical Sciences, Poland \\ ${ }^{3}$ Department of Computer Science and Statistics, Poznan University of Medical Sciences, Poland \\ ${ }^{4}$ Department of Cardiology, Poznan University of Medical Sciences, Poland \\ A - research concept and design; $B$ - collection and/or assembly of data; $C$ - data analysis and interpretation; \\ $\mathrm{D}$ - writing the article; $\mathrm{E}$ - critical revision of the article; $\mathrm{F}$ - final approval of the article
}

\section{Address for correspondence}

Tomasz Urbanowicz

E-mail: tk.urbanowicz@gmail.com

\section{Funding sources}

None declared

Conflict of interest

None declared

Received on April 30, 2020

Reviewed on July 3, 2020

Accepted on August 11, 2020

Cite as

Urbanowicz TK, Olasińska-Wlśniewska A, Michalak M, Straburzyńska-Migaj E, Jemielity M. Neutrophil to lymphocyte ratio (NTLR) as noninvasive predictor of pulmonary vascular resistance increase in congestive heart failure patients. Single center preliminary report. Adv Clin Exp Med. 2020;29(11):1313-1317.

doi:10.17219/acem/126292

DOI

10.17219/acem/126292

\section{Copyright}

Copyright by Author(s)

This is an article distributed under the terms of the

Creative Commons Attribution 3.0 Unported (CC BY 3.0)

(https://creativecommons.org/licenses/by/3.0/)

\begin{abstract}
Background. Nowadays, heart failure (HF) is a significant health problem due to steady increase in diagnosis, unpredictable acute decompensations and high mortality rate. Early risk stratifications of clinical deterioration are essential in preventing life-threatening events and ensuring proper patients management. Increased neutrophil to lymphocytes ratio (NTLR) above 6 is associated with the risk of re-hospitalizations and increased mortality.
\end{abstract}

Objectives. To compare NTLR and clinical, laboratory and hemodynamic results obtained from patients re-hospitalized within six-month intervals due to HF decompensation.

Material and methods. We evaluated 41 patients ( $n=36$ males (87\%) and $n=5$ females (13\%), mean age $50 \pm 10$ years) admitted to our hospital at least twice within six-month interval due to decompensation of chronic heart failure (CHF) between 2017 and 2019. All patients were divided into 2 groups depending on the NTLR values.

Results. There was no death in presented group during the observational time. We observed a significant difference in cardiac index $(\mathrm{Cl})-2.4 \pm 0.5$ compared to $2.6 \pm 0.6 \mathrm{~L} / \mathrm{m}^{2} / \mathrm{min}$ - between the $1^{\text {st }}$ and $2^{\text {nd }}$ admission ( $p=0.0356$ ). The right ventricle systolic pressure (RVSP) results related to NTLR level revealed significant difference ( $43 \pm 14 \mathrm{~mm} \mathrm{Hg}$ compared to $59 \pm 21 \mathrm{~mm} \mathrm{Hg}, p=0.0438$ ). We observed a significant increase of pulmonary vascular resistance (PVR) values (175 \pm 106 compared to $438 \pm 300 \mathrm{dyn}^{*} \mathrm{~s}^{*} \mathrm{~cm}^{-5}$, $p=0.0386$ ) in patients with NTLR above 6 .

Conclusions. Neutrophil to lymphocyte ratio may be an easy and suitable tool for monitoring of the HF progression. According to our study, the ratio correlates with PVR and RVSP increase.

Key words: neutrophils, heart failure, pulmonary hypertension, pulmonary vascular resistance 


\section{Background}

Nowadays, heart failure (HF) is a significant health problem due to steady increase in diagnosis, unpredictable acute decompensations and high mortality rate. ${ }^{1}$ Early risk stratifications of clinical deterioration are essential in preventing life-threatening events and ensuring proper patient management. ${ }^{2}$ Pulmonary hypertension secondary to $\mathrm{HF}$ is a factor of poor prognosis and has a significant influence on the severity of the disease. ${ }^{3}$

Increased neutrophil to lymphocytes ratio (NTLR) above 6 is associated with the risk of re-hospitalizations and increased mortality. ${ }^{4}$ In response to a variety of signals, neutrophils produce several cytokines and other inflammatory factors, including neutrophil serine proteases, peroxidases, proteinases, gelatinases, NADPH oxidase, and pentraxin 3. ${ }^{5,6}$ Cytokine hypothesis involving serum elevation levels of interleukin 1 (IL-1), tumor necrosis factor $\alpha$ (TNF- $\alpha)$, transmembrane suppression of tumorigenicity-2 receptor (ST2), IL-6, and galectin-3 in HF patients support inflammatory contribution of disease progression.?

We analyzed the clinical status, laboratory results and hemodynamic parameters in patients suffering from chronic heart failure (CHF), re-hospitalized within 6 months in our hospital.

\section{Material and methods}

We evaluated 41 patients $(n=36$ men $(87 \%)$ and $n=5$ women (13\%), mean age $50 \pm 10$ years) admitted to our hospital at least twice within a six-month interval due to decompensation of CHF due to HF with reduced ejection fraction (HFrEF) between 2017 and 2019. Twenty of them were diagnosed with dilated cardiomyopathy (DCM) and 21 with ischemic cardiomyopathy (ICM). Mean body mass was $85 \pm 15 \mathrm{~kg}$ compared to $87 \pm 16 \mathrm{~kg}$ on $1^{\text {st }}$ and $2^{\text {nd }}$ admission, respectively, and the mean height was $176 \pm 8 \mathrm{~cm}$. Concomitant diseases included diabetes mellitus (DM; 3 patients), chronic obstructive pulmonary disease (COPD; 2 patients), kidney dysfunction (2 patients), and a history of stroke (1 patient).

On admission and during hospitalization, laboratory tests, echocardiography, right catheterization, and 6-minute walking test (6MWT) were performed (Table 1). We analyzed baseline patients' demographics, change in functional class according to World Health Organization

Table 1. Differences in laboratory, echocardiographic and RHC parameters between $1^{\text {st }}$ and $2^{\text {nd }}$ hospitalization

\begin{tabular}{|c|c|c|c|}
\hline Parameters & $1^{\text {st }}$ admission & $2^{\text {nd }}$ admission & $\mathrm{p}$-value \\
\hline \multicolumn{4}{|c|}{ Whole blood count } \\
\hline Leukocyte count $\left[10 \mathrm{e} / \mathrm{L}=10^{9} / \mathrm{L}\right]$ & $7.3[6.3-8.4]$ & $7[5.8-8.3]$ & 0.0593 \\
\hline Neutrophil count $\left[10 \mathrm{e} / \mathrm{L}=10^{9} / \mathrm{L}\right]$ & $4.9[4.1-5.9]$ & $4.8[3.9-5.8]$ & 0.1561 \\
\hline Lymphocyte count $\left[10 \mathrm{e} / \mathrm{L}=10^{9} / \mathrm{L}\right]$ & $1.4[1.2-1.8]$ & $1.5[1-2]$ & 0.2461 \\
\hline NTLR & $3.5[2.5-4.7]$ & $3.3[2.2-4.4]$ & 0.7216 \\
\hline Hemoglobin [mmol/L] & 9.2 [8.7-9.6] & $8.9[8.5-9.5]$ & 0.3724 \\
\hline Albumin [mg/dL] & $40.3[38.5-42.8]$ & $40.5[38.5-41.9]$ & 0.4476 \\
\hline AST [IU/L] & $136[31-140]$ & 136 [34-139] & 0.8174 \\
\hline Creatinine $[\mathrm{mg} / \mathrm{dL}]$ & $101.4[85.9-128.2]$ & $94[83.3-122.9]$ & 0.8055 \\
\hline $\mathrm{CRP}[\mathrm{mg} / \mathrm{L}]$ & $2[1.0-6.2]$ & $2.8[1.1-8.8]$ & 0.2256 \\
\hline $\mathrm{BNP}[\mathrm{pg} / \mathrm{mL}]$ & $310[133.4-645.1]$ & $360[131.9-567.0]$ & 0.2158 \\
\hline proBNP [pg/mL] & 1652 [743-2618] & $1467[831-2627]$ & 0.4661 \\
\hline \multicolumn{4}{|c|}{ Echocardiographic parameters } \\
\hline $\operatorname{LVD}[\mathrm{mm}]$ & $75[67-80]$ & $73[65-82]$ & 0.8561 \\
\hline $\mathrm{RVD}[\mathrm{mm}]$ & 35 [32-39] & $35[31-37]$ & 0.4461 \\
\hline $\mathrm{RVSP}[\mathrm{mm} \mathrm{Hg}]$ & 40 [34-55] & $45[35-50]$ & 0.9652 \\
\hline LVEF [\%] & $20[15-25]$ & $20[15-25]$ & 0.5888 \\
\hline \multicolumn{4}{|c|}{ Right heart catheterization } \\
\hline PAPm $[\mathrm{mm} \mathrm{Hg}]$ & $32.5[23-44]$ & $29.5[21.5-40.0]$ & 0.3626 \\
\hline $\mathrm{CO}[\mathrm{L} / \mathrm{min}]$ & $4.7[3.9-5.5]$ & $5.3[4.6-6.0]$ & 0.0534 \\
\hline $\mathrm{Cl}\left[\mathrm{L} / \mathrm{m}^{2} / \mathrm{min}\right]$ & $2.3[2-2.7]$ & $2.6[2.4-2.9]$ & 0.0356 \\
\hline$P \vee R\left[d y n^{*} s^{*} \mathrm{Cm}^{-5}\right]$ & 151.5 [113-270] & 150 [106.0-218.5] & 0.1401 \\
\hline
\end{tabular}

Data presented as median [LQ-UQ]; LQ - lower quartile; UQ - upper quartile; AST - aspartate aminotransferase; BNP - natriuretic brain peptide; $\mathrm{Cl}$ - cardiac index; CO - cardiac output; CRP - C-reactive protein; EF - ejection fraction; LVD - left ventricle diameter; LVEF - left ventricle ejection fraction; NTLR - neutrophil to lymphocyte ratio; NT-proBNP - N-terminal prohormone natriuretic brain peptide; PAPm - mean pulmonary artery pressure; PVR - pulmonary vascular resistance; RHC - right heart catheterization; RSVP - right ventricle systolic pressure. 
(WHO) classification, results of 6MWT, and vital signs on admission (including heart rate, blood pressure). Laboratory data included brain natriuretic peptide (BNP), Nterminal prohormone of brain natriuretic peptide (NTpro-BNP), blood morphology, C-reactive protein (CRP), creatinine, alanine aminotransaminase (ALT), aspartate transaminase (AST), and NTLR. Echocardiography was performed in each patient at the admission, including left and right ventricle and atrial diameters, left ventricle ejection fraction (LVEF), presence of pericardial effusion, right atrial pressure (RAP) estimated by evaluating the inferior cava (IVC) size and change with respiration, and right ventricle systolic pressure (RVSP). The estimation of RVSP was based on the peak tricuspid regurgitation velocity (TRV) taking into account RAP as described by the simplified Bernoulli equation.

Right heart catheterization was performed in the catheterization lab. Pressure measurements were obtained, including mean RAP, right ventricle pressure (systolic, diastolic and end-diastolic), pulmonary artery pressure (systolic, diastolic and mean), and wedge pressure. Cardiac output $(\mathrm{CO})$ was measured with thermodilution with cold saline. The cardiac index $(\mathrm{CI})$, pulmonary vascular resistance (PVR), systemic vascular resistance (SVR), and transpulmonary gradient (TPG) were estimated.

All patients were divided into 2 groups depending on the NTLR values obtained from blood samples taken on admission. The values above or below 6 determined the division according to previous reports. ${ }^{7}$

\section{Statistical analysis}

Mean body mass, weight, $6 \mathrm{MWT}$ results and drugs daily dosages were presented as mean values and standard deviations (SD). The analyzed parameters were presented as medians and interquartile range (IQR), since data did not follow according to normal distribution (Shapiro-Wilk test); therefore, non-parametric tests were used. The comparison between data obtained during the $1^{\text {st }}$ and $2^{\text {nd }}$ admission was performed with Wilcoxon matched pairs test. Parameters between patients with NTLR value lower or greater than 6 were compared with Mann-Whitney test. Statistical analysis was performed using STATISTICA v. 13.3 (StatSoft Inc., Tulsa, USA). All tests were considered significant at $\mathrm{p}<0.05$.

\section{Results}

There was no death in the presented group during the observational time (2017-2019). The clinical evaluation of severity of HF decompensation was based on the New York Heart Association (NYHA) classification with mean NYHA functional class on the $1^{\text {st }}$ and $2^{\text {nd }}$ admissions $2.5 \pm 0.5$ and $3.2 \pm 0.5$, respectively. The indications for $2^{\text {nd }}$ admission were based on worsening in clinical symptoms regarding shortness of breath in 41 (100\%), easy fatigue in 35 (85\%) and lower extremities swellings in 38 (93\%) patients. Five (12\%) patients reported persistent cough.

There was neither a statistically significant difference in NYHA stage nor a correlation between NYHA stage and NTLR between both admissions. Moreover, the differences in BNP and NT-pro-BNP serum levels between both admissions were non-significant. The BNP serum levels were $435 \pm 409 \mathrm{pg} / \mathrm{mL}$ compared to $485 \pm 537 \mathrm{pg} / \mathrm{mL}$ on the $1^{\text {st }}$ and $2^{\text {nd }}$ admission, respectively. The NT-pro-BNP serum levels were $2103 \pm 1942 \mathrm{pg} / \mathrm{mL}$ compared to $2171 \pm 2239 \mathrm{pg} / \mathrm{mL}$ on the $1^{\text {st }}$ and $2^{\text {nd }}$ admission, respectively. The results of BNP serum levels related to NTLR were still insignificant (413 $\pm 418 \mathrm{pg} / \mathrm{mL}$ compared to $566 \pm 263 \mathrm{pg} / \mathrm{mL}$, respectively, $\mathrm{p}=0.0736)$. The results of NT-pro-BNP serum levels related to NTLR were not significant $(1961 \pm 1982 \mathrm{pg}$ compared to $2938 \pm 1979 \mathrm{pg} / \mathrm{mL}$, respectively, $\mathrm{p}=0.0933$ ). Detailed data is presented in Table 1.

There was no significant difference in echocardiographic parameters between both admissions including RSVP results ( $45 \pm 16 \mathrm{~mm} \mathrm{Hg}$ compared to $45 \pm 13 \mathrm{~mm} \mathrm{Hg}$, respectively). The RVSP results related to NTLR subgroups revealed a significant difference $(43 \pm 14 \mathrm{~mm}$ Hg compared to $59 \pm 21 \mathrm{~mm} \mathrm{Hg}, \mathrm{p}=0.0438$ ). Detailed data is presented in Table 2.

The clinical evaluation was also performed with $6 \mathrm{MWT}$ before discharge. The mean values of achieved distances on $1^{\text {st }}$ and $2^{\text {nd }}$ hospitalization were $356 \pm 41 \mathrm{~m}$ compared to $361 \pm 52 \mathrm{~m}$, respectively. The results of $6 \mathrm{MWT}$ during the $2^{\text {nd }}$ hospitalization in 2 NTLR subgroups were significantly different: $331 \pm 42$ compared to $378 \pm 39 \mathrm{~m}$, in patients with NTLR ratio above and below 6 , respectively.

We observed a significant difference in CI $(2.4 \pm 0.5$ compared to $2.6 \pm 0.6 \mathrm{~L} / \mathrm{m}^{2} / \mathrm{min}$ ) between the $1^{\text {st }}$ and $2^{\text {nd }}$ admission ( $p=0.0356)$. However, there was no relationship between NTLR level and CI.

There was no statistical difference in PVR values between admissions in studied group (212 \pm 170 compared to $190 \pm 117$ dyn*s* $\mathrm{cm}^{-5}$ ). However, we observed a significant increase in PVR values (175 \pm 106 compared to $438 \pm 300$ dyn ${ }^{*} \mathrm{~s}^{*} \mathrm{~cm}^{-5}$ ), $\mathrm{p}=0.0386$ in patients with NTLR above 6 .

Pharmacotherapy on $1^{\text {st }}$ admission included $\beta$-blockers, diuretics, eplerenone, and angiotensin-converting-enzyme inhibitors (ACE-I). The doses of diuretics and ACE-I were optimized increased during $1^{\text {st }}$ hospitalization. Pharmacotherapy regimes between both admissions are compared in Table 3.

\section{Discussion}

To the best of our knowledge, this is the first study presenting the correlation between NTLR and PVR and RVSP increase in patients with CHF. Heart failure is a challenging clinical problem with high mortality risk, exceeding $50 \%$ within 5 years. ${ }^{8}$ Therapy is focused on clinical improvement 
Table 2. Differences in laboratory, echocardiographic and RHC parameters between NTLR subgroups

\begin{tabular}{|c|c|c|c|}
\hline Parameter & $\mathrm{NTLR} \leq 6$ & NTLR $>6$ & $\mathrm{p}$-value \\
\hline \multicolumn{4}{|c|}{ Laboratory results } \\
\hline Leukocyte count $\left[10 \mathrm{e} / \mathrm{L}=10^{9} / \mathrm{L}\right]$ & $7.1[6.2-8]$ & $9.9[8.4-10.6]$ & 0.0036 \\
\hline Hemoglobin [mmol/L] & 9.2 [8.7-9.6] & $9.1[8.5-9.4]$ & 0.5922 \\
\hline Albumin [mg/dL] & $40.7[38.4-43.0]$ & 39.4 [38.6-40.4] & 0.5444 \\
\hline AST [IU/L] & $136[30-140]$ & $137[31-140]$ & 0.9410 \\
\hline Creatinine $[\mathrm{mg} / \mathrm{dL}]$ & $93.9[81.8-125.3]$ & $125.4[111.9-134.4]$ & 0.0797 \\
\hline $\mathrm{CRP}[\mathrm{mg} / \mathrm{L}]$ & $1.8[1.0-5.2]$ & $8.9[6.2-10.2]$ & 0.0676 \\
\hline $\mathrm{BNP}[\mathrm{pg} / \mathrm{mL}]$ & $240[122.1-574.4]$ & $519.4[356.1-650.4]$ & 0.0736 \\
\hline NT-proBNP [pg/mL] & $1293[674-2590]$ & $2775.5[1763-4626]$ & 0.0933 \\
\hline \multicolumn{4}{|c|}{ Echocardiography } \\
\hline LV [mm] & $73[64-80]$ & $80[75-84]$ & 0.0930 \\
\hline $\mathrm{RV}[\mathrm{mm}]$ & 34 [31-39] & 35 [35-37] & 0.3952 \\
\hline EF [\%] & $20[15-25]$ & $20[15-23]$ & 0.7930 \\
\hline $\operatorname{RVSP}[\mathrm{mm} \mathrm{Hg}]$ & $40[32-49]$ & $60[40-65]$ & 0.0438 \\
\hline \multicolumn{4}{|c|}{ Right catheterization } \\
\hline PAPm $[\mathrm{mm} \mathrm{Hg}]$ & $28.5[21.5-42.5]$ & $44[33.0-57.5]$ & 0.1005 \\
\hline $\mathrm{CO}[\mathrm{L} / \mathrm{min}]$ & $4.9[4.2-5.5]$ & $3.7[3.6-4.6]$ & 0.2244 \\
\hline $\mathrm{Cl}\left[\mathrm{L} / \mathrm{m}^{2} / \mathrm{min}\right]$ & $2.4[2.1-2.7]$ & $2[1.8-2.4]$ & 0.1227 \\
\hline$P \vee R\left[d y n^{*} s^{*} \mathrm{Cm}^{-5}\right]$ & $142[99.5-244.3]$ & $407[186-690]$ & 0.0386 \\
\hline
\end{tabular}

Data presented as median [LQ-UQ]; LQ - lower quartile; UQ - upper quartile; AST - aspartate aminotransferase; BNP - natriuretic brain peptide; CI - cardiac index; CO - cardiac output; CRP - C-reactive protein; EF - ejection fraction; LVD - left ventricle diameter; LVEF - left ventricle ejection fraction; NTLR - neutrophil to lymphocyte ratio; NT-proBNP - N-terminal pro hormone natriuretic brain peptide; PAPm - mean pulmonary artery pressure; PVR - pulmonary vascular resistance; $\mathrm{RHC}$ - right heart catheterization; RSVP - right ventricle systolic pressure.

Table 3. Pharmacology during both hospitalizations

\begin{tabular}{|l|c|c|}
\multicolumn{1}{|c|}{ Pharmacotherapy } & $\begin{array}{c}1^{\text {st }} \text { admission } \\
(n=41 \text { patients })\end{array}$ & $\begin{array}{c}2^{\text {nd }} \text { admission } \\
(\mathrm{n}=41 \text { patients })\end{array}$ \\
\hline $\begin{array}{l}\text { B-blockers: } \\
\text { Metoprolol [mg/daily] }\end{array}$ & $100 \pm 37.5$ & $100 \pm 25$ \\
number of patients & $4(10 \%)$ & $4(10 \%)$ \\
Bisoprolol [mg/daily] & $10 \pm 2.5$ & $10 \pm 2.5$ \\
number of patients & $2(5 \%)$ & $2(5 \%)$ \\
Carvedilol [mg/daily] & $25 \pm 12.5$ & $25 \pm 6.25$ \\
number of patients & $35(85 \%)$ & $35(85 \%)$ \\
\hline $\begin{array}{c}\text { Diuretics: } \\
\text { Furosemide [mg/daily] }\end{array}$ & $120 \pm 80$ & $180 \pm 40$ \\
number of patients & $41(100 \%)$ & $41(100 \%)$ \\
Eplenorone [mg/daily] & $50 \pm 1.25$ & $50 \pm 0.25$ \\
number of patients & $41(100 \%)$ & $41(100 \%)$ \\
Torasemide [mg/daily] & $10 \pm 3$ & $20 \pm 4$ \\
number of patients & $4(10 \%)$ & $6(15 \%)$ \\
ACE-l: & & $4.8 \pm 1.2$ \\
Ramipril [mg/daily] & $3.3 \pm 1.6$ & $41(100 \%)$ \\
number of patients & $41(100 \%)$ & \\
\hline
\end{tabular}

ACE-I - angiotensin-converting-enzyme inhibitors.

by blocking neurohormonal and sympathetic systems activation. ${ }^{9}$ In different types of cardiomyopathies, the trigger insult may be of inflammatory etiology with secondary immune system activation in response. The blood-recruited monocytes infiltrate the myocardium, causing further deterioration of the heart function. ${ }^{10,11}$ The persistence of inflammation after acute phases promotes adverse heart remodeling. ${ }^{12}$ In our study, we focused on a possible risk prognosis for future clinical deterioration assessed with NTLR. Neutrophils are known to be important effector cells in the immune system responding to multiple signals by producing inflammatory factors. ${ }^{13,14}$ They are involved in cell activation at the inflammatory sites. ${ }^{15}$ The link between HF development and clinical progression is strong and complementary to neurohormonal activation. ${ }^{16}$ Neutrophil to lymphocyte ratio above 6 is a known predictor for in-hospital mortality among patients with acute decompensations. ${ }^{17}$

In our study, there was a correlation noticed between NTLR and PVR values. Hence, the NTLR could be a possible prognostic factor for future clinical status deterioration among patients requiring readmission within a sixmonth time interval. Right heart catheterization (RHC) is a definitive tool for accurate hemodynamic monitoring. ${ }^{18}$ We found the PVR increased from $175 \pm 105 \mathrm{dyn}^{*} \mathrm{~s}^{*} \mathrm{~cm}^{-5}$ to $438 \pm 300 \mathrm{dyn}^{*} \mathrm{~s}^{*} \mathrm{Cm}^{-5}$ in the subgroup of patients with elevated NTLR. Although the BNP and NT-pro-BNP values were insignificant, the progression of the failing heart was noticed by hemodynamic results of heart function. In our study, we present the results confirming NTLR as a significant marker for future heart function deterioration. There was no statistically significant difference in RVSP between admissions, but an increase was noted $(42 \pm 14 \mathrm{~mm} \mathrm{Hg}$ compared to $59 \pm 21 \mathrm{~mm} \mathrm{Hg}$ ) regarding NTLR. 
Although the population did not differ in NYHA stage between both admissions, the clinical symptoms requiring hospitalizations may be related to increase in pulmonary hypertension evaluated easily using RSVP results in echocardiographic imaging. Among predictors in patients with left ventricular dysfunction, impaired function of right ventricle is believed to be an independent predictor of less than $30 \%$ survival within 5 years. ${ }^{19}$ Echocardiography of right ventricle hemodynamics is focused on its function and on risk estimation of pulmonary hypertension. Both parameters are significant for patients' prognosis including disease severity and survival. ${ }^{20} \mathrm{We}$ present the results of the study, indicating NTLR as an easy laboratory tool of parallel significance related to $\mathrm{RHC}$ results.

We noticed that despite clinical deterioration, heart catheterization revealed an increase in CI. The initial results were $2.4 \pm 0.52 .6 \pm 0.6 \mathrm{~L} / \mathrm{m}^{2} / \mathrm{min}$ and changed to $2.6 \pm 0.6 \mathrm{~L} / \mathrm{m}^{2} / \mathrm{min}(\mathrm{p}=0.0356)$. The differences may be explained by pharmacotherapy optimization including diuretics and ACE-I doses increase. However, there was no relationship between NTLR level and CI.

The most significant result of the study is connected to the NTLR to PVR estimation with RHC. Pulmonary vascular resistance is a lone predictor of poor outcomes according to previous studies in patients suffering from HF. ${ }^{21}$ Moreover, the PVR increase indicates ominous disease progression. ${ }^{22,23}$ The results of our study suggest that NTLR can be a suitable, quick and easy tool for assessing the risk of PVR progression stratification in patients suffering from circulatory insufficiency.

\section{Conclusions}

Neutrophil to lymphocyte ratio may be an easy and suitable tool for monitoring HF progression. According to our study, the ratio correlates with PVR and RVSP increase.

\section{ORCID iDs}

Tomasz Kamil Urbanowicz (10 https://orcid.org/0000-0001-8080-2764 Anna Olasińska-Wlśniewska (i) https://orcid.org/0000-0002-4213-8708 Michał Michalak (1) https://orcid.org/0000-0002-2852-3984 Ewa Straburzyńska-Migaj (i) https://orcid.org/0000-0002-0545-3370 Marek Jemielity (1) https://orcid.org/0000-0003-2442-4644

\section{References}

1. Ponikowski P, Voors AA, Anker SD, et al; Authors/Task Force Members; Document Reviewers. 2016 ESC Guidelines for diagnosis and treatment of acute and chronic heart failure: The Task Force for the diagnosis and treatment of acute and chronic heart failure of European Society of Cardiology (ESC). Developed with the special contribution of the Heart Failure Association (HFA) of ESC. Eur J Heart Fail. 2016;18(8):891-975.
2. Wang X, Fan X, Ji S, Ma A, Wang T. Prognostic value of neutrophil to lymphocyte ratio in heart failure patients. Clin Chim Acta. 2018;485: 44-49.

3. Berthelot E, Bailly MT, Hatimi SE, et al. Pulmonary hypertension due to left heart disease: Pulmonary hypertension due to left heart disease. Arch Cardiovasc Dis. 2017;110(6-7):420-431.

4. Ni J, Wang H, Li Y, Shu Y, Liu Y. Neutrophil to lymphocyte ratio (NLR) as a prognostic marker for in-hospital mortality of patients with sepsis: A secondary analysis based on a single-center, retrospective, cohort study. Medicine (Baltimore). 2019;98(46):1-5.

5. Rosales C. Neutrophil: A cell with many roles in inflammation or several cell types? Front Physio. 2018;9:113-129.

6. Selders GS, Fetz AE, Radic MZ, Bowlin GR. An overview of the role of neutrophils in innate immunity, inflammation and host-biomaterial integration. Regen Biomater. 2017;4(1):55-68.

7. Zhang Y, Bauersachs J, Langer HF. Immune mechanisms in heart failure. Eur J Heart Fail. 2017;19(11):1379-1389.

8. Dick SA, Epelman S. Chronic heart failure and inflammation: What do we really know? Circ Res. 2016;119(1):159-176.

9. Drazner $\mathrm{MH}$. The progression of hypertensive heart disease. Circulation. 2011;123(3):327-334.

10. Bajpai G, Bredemeyer A, Li W, et al. Tissue resident CCR2- and CCR2+ cardiac macrophages differentially orchestrate monocyte recruitment and fate specification following myocardial injury. Circ Res. 2019;124(2):263-278.

11. Gentek R, Hoeffel $G$. The innate immune response in myocardial infarction, repair, and regeneration. Adv Exp Med Biol. 2017;1003:251-272.

12. Mortensen RM. Immune cell modulation of cardiac remodeling. Circulation. 2012;125(13):1597-1600.

13. Mayadas, TN, Cullere X, Lowell CA. The multifaceted functions of neutrophils. Annu Rev Pathol. 2014;9:181-218.

14. Nauseef, WM, Borregaard N. Neutrophils at work. Nat Immunol. 2014; 15(7):602-61.

15. Casanova-Acebes M, Pitaval C, Weiss LA, et al. Rhythmic modulation of the hematopoietic niche through neutrophil clearance. Cell. 2013;153(5):1025-1035.

16. Van Linthout 1, Tschöpe C. Inflammation: Cause or consequence of heart failure or both? Curr Heart Fail Rep. 2017;14(4):251-265.

17. Cho JH, Cho HJ, Lee HY, et al. Neutrophil-lymphocyte ratio in patients with acute heart failure predicts in-hospital and long-term mortality. J Clin Med. 2020;9(2):557.

18. Kałużna-Oleksy M, Araszkiewicz A, Migaj J, Lesiak M, StraburzyńskaMigaj E. "From right to left": The role of right heart catheterization in the diagnosis and management of left heart diseases. Adv Clin Exp Med. 2017;26(1):135-141.

19. Zelt JGE, Chaudhary KR, Cadete VJ, Mielniczuk LM, Stewart DJ. Medical therapy for heart failure associated with pulmonary hypertension. Circ Res. 2019;124(11):1551-1567.

20. Annone U, Bocchino PP, Marra WG, et al. Echocardiographic estimation of right ventricular wall tension: Haemodynamic comparison and long-term follow-up. Pulm Circ. 2019;9(4):2045894019895420.

21. Naeije R, Gerges M, Vachiery JL, Caravita S, Gerges C, Lang IM. Hemodynamic phenotyping of pulmonary hypertension in left heart failure. Circ Heart Fail. 2017;10(9):e004082.

22. Dragu R, Rispler S, Habib M, et al. Pulmonary arterial capacitance in patients with heart failure and reactive pulmonary hypertension. Eur J Heart Fail. 2015;17(1):74-80.

23. Urbanowicz T, Straburzyńska-Migaj E, Katyńska l, et al. Sustained improvement of clinical status and pulmonary hypertension in patients with severe heart failure treated with sildenafil. Ann Transplant. 2014;19:325-330. 